Stream: Inspiring Critical Thought

2019, Vol 11(1), 21-33

(C) The Author(s), 2019

http://journals.sfu.ca/stream

\title{
Exploring Middle-Class Malaysian Parents' Perceptions and Concerns About Children's Internet Usage
}

Simranpreet Kaur Hansaram

York University, Toronto

\begin{abstract}
The growing number of children internet users are causing parents to worry. While there are many researches in the Global North, very few studies are done in the Global South. The study aims to bridge this gap with a study of Malaysia, a Global South country. Using a contextual approach, this research investigates middle-class Malaysian parents' perceptions and concerns about their children's internet usage. Qualitative in-depth interviews were conducted with seven parents, whose children - aged from five to eighteen - are active internet users. The analysis of the interviews revealed three major themes; firstly, parents make evaluative judgments about internet contents and platforms; secondly, children's age determines use and device ownership; and thirdly, Malaysian parents used mediation strategies unique to Malaysia: they employ spies among their children and enlist help from older children. The analysis further revealed two generalized Malaysian parents' fears about the internet: foreign culture influencing the dominant culture and apprehensions about new technologies.
\end{abstract}

Keywords: parents' perceptions and concerns, moral panic, children's internet usage 
The widespread use of the internet among children in recent years has contributed to parental concerns (Livingstone, 2007; Livingstone \& Haddon 2009; Livingstone \& Helsper, 2008; Livingstone, Haddon, Görzig, \& Ólafsson, 2011; Mascheroni, Dreier, Chaudron, \& Lagae, 2015; Livingstone, Mascheroni, \& Staksrud, 2015). Yet, at present, there is abundant research in the Global North and very little in the Global South. For instance, there is the European Union Kids Online study (2015) and a Pew Research study about the situation in the U.S. (2016). This could be related to the fact that, in many Global South countries, "use of ICT and the internet is scarce" (Byrne and Burton, 2017, p. 42). But with the recent changes to the Global South's digital ecology, the region now presents itself as equally significant for such research. This change includes becoming economically important and having extensive numbers of internet users expanding to marginalized groups in rural districts (The Organization for Economic Co-operation and Development [OECD], 2011, p. 13). The Global Kids Online project (2016) is making attempts to globalize such research. Nevertheless, there is a limited inclusion of Argentina, South Africa, India, and the Philippines. These changes are also a consequence of the proliferation of cheaply manufactured mobile phones, faster internet speeds and cheaper data. This is evidenced by the fact that today there are 1.25 billion mobile technology users in the AsiaPacific region (https://www.statista.com/statistics/2017). Further supporting this notion is research by Livingstone and Bulger (2014), suggesting that there are more young people using the internet in the Global South, therefore leading to increased parental concerns with new risks to their children's well-being in the online environment (p. 318). As such, a study in this region is timely and critical.

With the mentioned development in the Global South, it is tempting to extrapolate the findings of parental concerns about children's internet usage from the Global North to the Global South. Nonetheless, there are some social, economic and media use factors in the Global South that make it a distinct environment: "This includes recognizing specific meanings in a given context such as meanings of 'internet' and 'parents' (Byrne, Kardefelt-Winther, Livingstone, \& Stoilova, 2016, p. 458)". Moreover, "changes in the global context and findings from a specific region contributes to non-binary perceptions and literature on parents' concerns and children's internet usage" (Livingstone \& Bulger, 2014, p. 318).

\section{Research objective and methodology}

The Global South is under-researched, and using data from the Global North is unsuitable, due to significant cultural differences. Indeed, meanings change across different contexts. My research aims to bridge this gap by carrying out a study in Malaysia, a Global South country. The objective of the study is to explore middle-class Malaysian parents' perceptions and concerns about their children's internet usage. The research is timely, since Malaysian parents are becoming more and more concerned with children's internet usage, just like parents in European countries and North America. Additionally, Malaysian parents' anxieties are also fueled by an increasing number of children with access to cheaper and faster internet. The findings from this research can offer an evidence-based study and inform parents and policymakers about parental perceptions and concerns on children's internet usage. The research can also provide an empirical evidence that contributes to systematic knowledge in communication scholarship. I will answer the research questions using data collected from in-depth interviews with seven parents, who have internet access at home, data on their phones, and children who are active internet users. Since digital literacy (Eshet-Alkalai, 2004, p. 102) is important in the context of this research, I chose middle-class Malaysian parents for both their availability of access and high participation in the digital environment. They also represent a population who can answer the research questions based on their personal experiences.

The research approach of this study is qualitative and informed by a social constructivism perspective, procedures of grounded theory and intensive interview using open-ended questions. 
“The goal of the research is to rely on the participants' view of the situation being studied and to understand subjective meanings negotiated socially and historically" (Creswell \& Creswell, 2018, p. 8). The approach also addresses the processes of interactions among individuals and focuses on specifics contexts in which people live and work, to better understand the historical and cultural settings (Creswell, 2018, p. 8). Further, according to Rubin and Rubin (2005), this perspective is suitable as it "combines different individuals' detailed report of a particular event and interpreted through participants' own cultural lenses" (p. 30). The procedure of grounded theory is in accordance with the topic of study - that is, to "derive a general, abstract theory of a process, action or interaction grounded in the views of the participants" (Creswell \& Creswell, 2018, p. 13). Such methods increase flexibility when gathering data, because "they foster following up on what is happening and give more focus as data can be coded and categorized as they are collected" (Charmaz, 2014, p. 26).

As part of this research method, intensive interviewing (using open-ended questions) is used, because the study seeks to "understand participants' language, meanings, actions, emotions, and body language" (Charmaz, 2014, p. 58). The method is also chosen because "through interviews, the participants will be gently guided in the discussions, leading through stages, asked focus questions and encouraged to answer in-depth and at length" (Rubin \& Rubin, 2005, p. 110). The study is primarily guided by Sorbrings' (2014) research on parental concerns about children's internet usage. Secondly, Cohen's moral panic theory is applied to examine the parents' perceptions and concerns over children's media consumption.

\section{Literature Review}

\section{Parents' perceptions and concerns about children's internet usage}

The review of past literature on parents' concerns and perceptions about children's internet usage points to four major themes. Firstly, parents worry that the internet affords connectivity in a wider spectrum of subjects, and therefore requires further understanding inside the familial environment. Sorbring writes "parents reported concerns about children becoming or getting isolated and addicted to the internet, eschewing physical activity, and what they come into contact with while using the internet" (p. 76). Prensky (2001) linked this to parents being new to technology, akin to "digital immigrants" who have problems conceiving the technicality, materiality and mechanism and maneuvering in this new "normal". Additionally, parents consider the digital space a frightening place for their children, "digital natives" who are born in the age of technology (Livingstone \& SeftonGreen, 2016; Sorbring, 2014; Prensky, 2001). On the contrary, Helsper and Enyon (2009) suggest "gender, education, experience and breadth of use also play a part" (p. 14).

The second body of literature shows that parents' concerns about children's internet usage are fueled by affordability: smaller, portable devices, with digital media becoming increasingly complex. For example, the current devices encourage solitary activity and are often used in the privacy of the children's room. In this case, parents' mediation practices (such as having computers in a common room, checking the browser, and installing monitoring software) are problematic in this new setting. Several researchers also argue that, given the complexity of digital media, traditional mediation strategy to manage children's online activities have become ineffective (Haddon \& Vincent, 2015; Mascheroni \& Ólafsson, 2014). On the other hand, Terras and Ramsay (2016) suggest that parents themselves implicitly set standards by validating practices of children's internet usage, since they often engage in several unsafe internet behaviors and excessive phone use in the home environment (p. 6).

Thirdly, scholars suggest that parents are also concerned with their lack of digital competencies, while children are skilled adopters of digital media. For example, some parents worry children can decode technological apps set by them to filter and block content (Prensky, 2001; Livingstone \& 
Haddon, 2009; Hasebrink et al., 2008; Livingstone et al. 2011). These researchers argue that children have superior internet knowledge, enabling them to deal with the changing nature of internet technologies and devices. Additionally, when parents lack digital competencies, negotiating the supervision of children's internet usage becomes a challenge, to the point that "they are contemplating leaving it to the teachers to sort things out" (Vincent, 2015, p. 9). Sorbring (2014) supports this notion when she writes that "a combination of insecurity, and lack of knowledge about the internet cause parents' greater worry" (p.90). Along similar lines, Soldatova and Zotova (2013) write that parents should allow their children to explore the environment on their own, since "in the course of intense interaction with this environment, children have learned how to use it as a tool for solving problems" (p.57). Staksrud and Livingston (2009) also suggest that children see ambivalent internet content (such as pornography) "cool, fun and do not think too much about it" (p. 374). These observations are affirmed by Prensky (2001) who argues that "smart adult[s] should accept that kids born into any new culture learn the new language easily" (p. 3).

Finally, several studies indicate that parental concerns are based on children's age, which determines both internet usage and device ownership. Generally, parents are more concerned about children who are younger than twelve, but often their rules and monitoring apply to all ages. As revealed in findings from Ofcom (2017, p. 186-187), even though parents trust their children's safe internet use, they are concerned with how much time they spend online. The rationale is that children of this age do not know how to react appropriately to different types of contents. This is notwithstanding to parents' awareness of their children's specific internet safety skills to cope with difficult online situations such as knowing how to change the filter or the contact setting. However, according to the Pew Research report (2016, p. 9), regardless of children's age, parents say they check their children's web browsing history - particularly for those younger than twelve. These parents are more likely to use tech-based tools to block or keep an eye on the internet and limit the time of use. Since more children above the age of twelve have their own device and social media accounts, parents admit to following their children on social media, checking their profiles, knowing their passwords and tracking online histories. However, parental rules on internet usage still apply to older children. Often, parents will carry out digital grounding (take the device away from children) if these rules are not followed.

As scholars agree that parents are concerned about their children's internet usage, the research literature also points out that parents often lack understanding of the internet's potentials, are insecure about their own technological skills, and make futile efforts to play catch-up with their children (early skilled adopters). These reasons are not to be discounted, particularly since, despite the parents' claims that children are young and need their guidance, there is growing evidence of children's ability to manage their online activity.

\section{Parents' perceptions and concerns about children's internet usage and moral panic}

Despite the arguments made by some scholars that parents should not unduly worry about their children's internet usage, past studies bring to light parental concerns with the newer social media sites and services. There is evidence that supports this notion in several research findings and major studies (such as EU Kids Online, 2015; Ofcom 2016; Pew Research, 2016 and Global Kids Online, 2016). Nonetheless, as other scholars argue, this is the case of societies being overly concerned with new technologies. According to Cohen (2002), "sometimes societies undergo periods of moral panic when they are subject to a condition, episode, person or group of persons emerging to become a threat to societal values and interests." (p. 1). Generally, moral panic is a feeling of fear that spreads among many people. The media often are key players in disseminating information that may generate concern, anxiety or panic, so the public must exercise caution. As Cohen (2002) points out, there is "media exaggeration and distortion and there are different ways in which images are coded and the 
operation of some sort of 'credibility gap' in the mass communication process" (p. 71). Often enough, however, the object of moral panic passes over and is forgotten, until the next phenomenon piques the interest of society at large.

Buckingham (2012) suggests "there is always a moral panic around children's media usage, because their consumption is often perceived as an urgent problem" (p. 414). For instance, there's growing uneasiness with the popularity of toys "unboxing" videos on the internet. According to Craig and Cunningham (2017), these videos show children opening a surprise egg that consists of toys. While the videos seem ordinary enough, they manage to get children "hooked, modelling after them, and self-narrating the aesthetics practices featured in these videos in their everyday activities such as brushing teeth" (p. 78). McRobbie and Thornton (1995) argue this is the case with the practices of media becoming embedded in everyday practices (p. 570). But the Ofcom report (2017) labels these "newer forms of online advertising that are hard for children to identify." So worried parents are calling for greater regulations on such videos that aim at vulnerable populations. However, Facer (2012) suggests these concerns are "often triggered by the media who have an interest in fueling and maintaining parents' anxiety to retain their readerships" (p. 409). Having said that, "moral panic is also a concern as reactions are out of proportion to the real and present danger a given threat poses to the society" (Goode \& Ben-Yehuda, 1994, p. 156). The repercussion can include changes in legal and social policy, or even in the way that society conceives itself. As fear is heightened and concerns are exaggerated, the situation becomes problematic. Cohen (2002) attributes this to "sensitization, where behaviour, condition, or phenomenon that is routinely ignored take center stage. People tend to notice them more, and police widen their law enforcement efforts, to diffuse and control" (p. 8691). Cohen (2002) also asks what does the moral panic tell us about how society is constituted, how it works, how it changes over time? Buckingham (2011) points out "There is a need to understand these circumstances in the context of broader historical changes in family life" (p .144).

\section{The importance of context}

Although there are several studies about parental concerns in the Global North, generalizing the results from these studies to inform parents and policymakers in the Global South is not necessarily practical. Instead, we can examine how far the research and policy agendas framed in the Global North are relevant in the Global South. For instance, meanings might become dissimilar in a different context. According to Livingstone and Bulger (2014, p. 323), in the Global North, internet is perceived as a "ladder of opportunities where children engage in basic activities such as information search and single-player gaming." The Global North body of research on parental concerns about children's internet use is influenced by demographic factors, psychological and familial factors, children using private networks and original names for social media profiles, more internet-savvy parents and schools informing policymakers. In the Global South, the places that offer internet access are unsupervised (such as cyber-cafes), parents are not internet-savvy, there's a general low level of regulation, children's use of public networks and fake names in social media profiles is generalized, and there's a more prominent general preoccupation to meeting the basic necessities of life. These are important considerations in researching this topic. Livingstone and Haddon (2009) express a similar notion, and suggest that, even across Europe, parental perceptions about how children cope with online risks vary from Northern to Southern and Eastern Europe (p. 17). Kirwil (2009), also emphasizes that "parents' mediation of children's internet use varies significantly by culture" ( $p$. 396). With the bulk of research literature focusing on the Global North, carrying out this study in Malaysia will provide better insights for Malaysian parents and policymakers. 


\section{Findings}

The analysis of the interview data brings into evidence three major themes: a) parents make evaluative judgments about internet content and platforms; b) use children's age to determine internet usage and device ownership; and c) adopt strategies to mediate children's internet usage. Two strategies are unique to Malaysian parents: spies among children and help from older siblings.

As part of the first theme, parents identify certain types of content and contacts allowed on internet platforms. These results are pursuant to research from Ofcom (2017); Pew Research, (2016); and Global Kids Online (2016). Malaysian parents perceive four types of internet content as "good": education, edutainment, entertainment and play, and creativity or skill enhancement. The first "good" type internet content is education. It is related to American history, medical and sciences (the TV series Bones), and wildlife (Coyote Peterson), online dictionary, and thesaurus (as identified by participants KK, RS \& RA). The educational content also teaches children about being careful and not becoming crime victims (TV series Law and Order and Bones). Participant KK confesses that her daughter learns about surgery, curing illnesses, and takes notes about how fatality happens.

The second "good" internet content is edutainment. This includes content on YouTube Kids, and other platforms that promote learning through repeating words and phrases, alphabets, and numbers through songs and nursery rhymes (as indicated by participants RA, DJ, \& SR). Participants DJ and RA further acknowledge that their children under the age of 5 learned the English language from watching videos on YouTube, such as ChuChu TV Nursery Rhymes and Little Baby Bum. Other examples include Dora, Mickey Mouse, Paw Patrol, and Peppa Pig, about characters exploring new places, culture, diversity, citizenship, solving problems and learning about kindness and loyalty.

The third type of "good" internet content relates to showcasing values and positive role models, such as Unicorn. The fourth group of internet content regarded as "good" by Malaysian parents promotes creativity and skills enhancement. This includes "How to do/make something" videos, such as cooking, baking, putting on makeup, and the making of miniature volcanoes; slime, play dough, and bubbles. Other examples are drawing techniques (anime) and how to play musical instruments (as per participant RS). The Malaysian parents consulted in this study also include creative nail art videos and Minecraft in the "good" internet content category.

There are also five types of internet content which Malaysian parents consider as "bad" or "wrong" for their children. These include: content showing negative actions, actions inappropriate for young ages, violent actions, actions contrary to religious values, or those promoting hate and extreme religious views.

The first "bad" type of internet content, as perceived by the parents, show actions such as people taking drugs, smoking, and drinking alcohol (as per participants RA \& DJ). The second type refers to pornography - as stressed by participant RA, "they are simply not age-appropriate." The third category covers violent or dangerous activities, such as the Blue Whale Challenge. Participant RS states her worries that this type of content dares children to carry out risky and dangerous acts, asking the participant to commit suicide in the end. The fourth "bad" type of content, perceived as going against Malaysian religious values, includes music videos of popular, scantily-clad artists, as well as song lyrics or movie lines with vulgar words. The fifth type promotes hate of other religions, killing in the name of religion, or solving problems through gun violence. Participant RS emphasizes that these contents have capabilities to brainwash all children. This is especially valid for older children who have "the capacity to act, such as joining the Islamic state (IS) group" (designated a terrorist organization by the United Nations).

While Malaysian parents place demarcations on "good" and "bad" internet content, on some occasions, they are also concerned about some content usually considered "good". For instance, participants RK, KK and NZ state their worries about Korean content. Participant KK discloses, for instance, that such content (which includes beauty standards) generate her daughter's negative body 
image, through comparison. As a result, the daughter "voiced out intentions of undergoing cosmetic surgery to look like the Korean actresses." Expressing similar concerns, participant NZ says her daughters are disregarding Malaysian culture, insisting on "watching Korean movies, learning to cook and eat Korean food at all times." According to Jae, Seul and Sang (2017), this is an example of viewers "fulfilling their quest for "Koreanness" (Hallyu - a global phenomenon designating the popularity of South Korean dramas and K-Pop) as they also consume lifestyle items such as food, cosmetics, fashion, and travel" (p. 2301). Further parental concerns about children's internet usage are prompted by the display of "anger and impatience" when they must wait for their favourite internet content on YouTube (as indicated by participants RA and DJ). Finally, parents are also concerned with children's "imitating actions without knowing the impact," such as carrying out science experiments without adults' supervisions (as per participants DJ \& SR).

Malaysian parents also perceive internet platforms as having both positive and negative values. For example, they assume that there are bad potentials of Facebook, Instagram and WhatsApp. Participants KK, RS and RK also support this notion. They underline that "these are places children meet strangers, and where they can then arrange for a date." Moreover, people with bad intentions "can find one's whereabouts and cause eventual physical harm." Participant RK worries about the internet platforms, due to the permanence of the information posted in cyberspace: what is posted today remains in the online environment and may affects children's future reputation and jobs potentials. Further, participant RA maintains the platform is easy to hack. It is a commonplace for fake news. There are also too many people who have access to one's profile through the "Likes" and "Sharing" buttons. Therefore, participant RS discounted Facebook from her children's online activity, as she regards it as a "bad" platform.

On another note, Malaysian parents regard Instagram and WhatsApp as a place for good forms of communication. They deem getting "likes" and "followers" are positive for their children's self-image. However, they view continuous posting as obsessive behaviour, and have negative effect on selfesteem and self-acceptance. Nonetheless, participants DJ and SR, also regard these services as "bad" platforms, because they are used to harm others' reputations (for example, posts of people smoking or wearing skimpy outfits). These actions are not acceptable in Malaysian culture, which emphasizes Asian and religious values. Particular attention is paid to cases of shaming another person in public and the consequences that transpire in the offline environment. As Ingraham and Reeves (2016) point out, the internet allows public shaming, and this action becomes easier and more common than ever (p.463). This is also emphasized by participant DJ, who states: "In this case, being Insta-famous is garnering attention in the wrong way and from here onwards, Instagram is used as platforms for cyberbullying".

Parents also considered internet platforms that use children for toy demonstration videos by toymaking companies as "bad". Examples include Ryan ToysReview, FunToys Collector Disney Toys Review, ToyPudding TV, Eggs Kinder surprise or play-doh eggs, and Toys and me. In these shows, children play with cars, trucks, superheroes, "unboxing" or opening surprise (Kinder) eggs, and PlayDoh. Thus, children are becoming marketing promotion tools for toymakers. Craig and Cunningham (2017) refer to this phenomenon as "professionalizing-amateur content creators (children), engaging in content innovation and media entrepreneurship to aggregate global fan communities and incubate their own media brands" (p. 78). According to participants DJ and RA, after watching such videos, children often ask parents to purchase "unnecessary and expensive" toys. This is referred to as "pester power" and refers to "children's increasing autonomy to nag and influence family purchase decisions" (Buckingham, 2011, p. 152). However, Buckingham (2011) also draws our attention to "limited evidence on children's pester power. It more likely the behavior is encouraged by children's restricted disposable income. And the power to decide still lies with the parents" (p.155). Nonetheless, some Malaysian parents regard this "pestering" as an outcome of watching commercial YouTube videos disguised as educational content. 
Other examples of internet platforms that Malaysian parents are concerned with are Movies123.com, Netflix, and YouTube. Parents worry that these internet platforms allow "engaging, searching and downloading many videos and songs" (Participants RS, DJ \& SR). They suggest these services encourage children to download unlimited content, which they will "binge watch" or listen to at a later stage. Participant RS surmised this as a "loss of valuable time such as communications with others, studying or playing outside family homes." In supporting this notion, participant RK describes how her son became an "insomniac and worrisome freak, trapped in binge-watching videos about US government cover-ups of alien invasions." Participants KK and NZ define this phenomenon as being carried away, "watching many hours of Korean movies instead of doing homework." Malaysian parents are also concerned about other internet platforms supporting online shopping, violent video games, and online gambling. Participant RS also mentions pop-ups on websites, which could expose her children to inappropriate content.

Apart from internet content and platforms, Malaysian parents are concerned about the financial cost related to data. For example, although participant RS "trusts her children will tell their online activities", she caps data on her children mobile phones. This is consistent with Haddon and Vincent (2015) which show that "parents restrict their children's internet usage because of social and economic reasons" (p.28). Even so, Malaysian parents are not concerned with the type of devices used by children to explore the internet, or their children's increasing screen time with mobile phones. This is contrary to Terras and Ramsay's (2016) findings that "increasing screen times in mobile phones worry parents, because they limit children's social experiences" (p.4).

The age of children also determines internet usage and ownership of a device. For instance, Malaysian parents control internet usage for children below the age of nine. This includes rules: the parents must be in the vicinity, the use of parents' or family shared devices can only occur with permission, within a limited timeframe, and the usage is limited to watching edutainment content (participants DJ, RA, \& SR). Yet, parents always allow children at this age to use the internet irrespective of school days or weekends. This is in accordance with Nikken and Jansz (2014), who suggest parents may still want to be involved with their children's digital use and learning, especially the younger ones (p. 252). However, the conditions change for children aged nine to thirteen. During school days, internet usage is time-limited and only supposed to help with homework (participants RK \& KK). But parents also consent to the use of their devices to communicate with friends or teachers about school work and activity. Moreover, there are flexible hours during the weekend, school breaks, and public holidays. On that premise, parents do not have to be in the same room with their children when they use the Internet. Some Malaysian parents also allow device ownership but without a mobile number (as per participant RA). When children rely on Wi-Fi, parents who are apprehensive with what children might encounter online can switch off the internet connections at will. As suggested by Livingstone et al. (2011), "children should be the focus of safety measures because they are less well-equipped to manage risks themselves" (p.132). However, there are more freedoms given by Malaysian parents on internet usage for children aged thirteen and above, as their internet usage encompasses broader use. In this context, Malaysian parents view device ownership as crucial for children, since it supplements communications and education. These findings conform to Nikken and Janz (2014), who suggest that parents adjust mediation practices based on children's age (p.264).

In a nutshell, the findings show that, although parents restrict children's experience with the internet, they also support children's learning from the Internet. Dias et al. (2016) suggest this represents "a shift of parents from 'gatekeeper' towards 'scaffolder' that adopt an instructive and supportive position towards digital technologies" (p. 424). Malaysian parents used to give devices only to older children - such as when they leave family home to attend college. This is to support family communication and relationships (participant RK). However, the internet has changed the social environment, thus lowered children's age of having their own device. One of the primary 
reasons for Malaysian parents allowing their children to have mobile phones is that the devices are important during an emergency. Terras and Ramsay (2016) propose such devices are "means to make sure safety as it allows contact with parents if necessary" (p. 5). Similar reasons also motivate participants NZ and DJ to give mobile phones to their children who are at boarding schools. In addition, some schools encourage the use WhatsApp as a medium of communication and for accessing the teaching and learning platforms.

The third theme uncovered in this study refers to two mediation strategies unique to Malaysian parents: spies among siblings and help from older children. In the first case, Malaysian parents recruit spies among their children, to find out who breaches the parents' trust of internet usage. According to participants RS and RA, they tell their children that "they must take care of each other and report to mummy if anything happens." In many instances, the spy is always the younger child (Participant RS). As the "baby" of the family, they spend more time with parents, while older children demand independence and privacy (participants RA \& KK). This makes them more willing to share information with the parents (participants RA \& RS). As part of the second strategy, Malaysian parents enlist help from their elder children to monitor the younger children's internet usage. For example, participant SR enlisted her 20-year old daughter's assistance because she is not a techsavvy person. Other Malaysian parents also agree with this tactic, since they cannot always be around to supervise children's internet usage (according to participants RK \& RS). As Nikken and Schols (2015) suggest, "older siblings may also serve as a role model for their younger siblings" (p. 3434).

\section{Discussion and Conclusion}

The aim of this research is to collate and appraise evidence pertaining to middle-class Malaysian parents' perceptions and concerns about their children's internet usage. In doing so, the wider objectives were to expand what other researchers and policymakers had to say about broader questions. For example, what do parents' perceptions and concerns reveal about Malaysian parents and their culture? The results of this study show Malaysian parents outlining two concerns: fear of foreign culture influencing the dominant culture, and fear of technology.

The first fear stems from children's engagement with popular content from East Asia (mainly Korean and Japanese content), as well as content from Western countries. Malaysian parents express general uneasiness about children appropriating values of Hallyu or Weeboo (a term designating non-Japanese persons who demonstrate a strong interest in aspects of Japanese culture, such as anime) and Western content (such as music videos that portray artists in revealing clothes). This resulted in parents engaging in pushback measures, to maintain what they view as Malaysian family values, centered on religion. For example, Malaysian parents impose restrictions on internet content and platforms that are not age-appropriate and do not depict Islamic teachings, such as wearing modest clothes (according to participants RS, DJ, \& NZ).

The second fear revolves around parents feeling unable to cope with the fast development of technology, which includes media devices and the internet. Participant RK attributes this to "children's changing media consumptions and parents not being able to keep up with the technology." This also exhibits a digital literacy generational gap between parents and children. Consequently, parents' concerns could arise from them having fewer digital skills compared to their children (Clark 2011; Nikken and Schols 2015). In this respect, the parents' concern reveals a struggle over generational order.

Although parents display genuine concerns, they may also be scapegoating the internet for broader issues. According to Buckingham and Jensen (2012), "these are symptoms of more general anxieties provoked by the rapid pace of social change, entail forms of displacement and concerns about broader issues which are typically transferred to or more narrowly focused on specific issues" (p. 416). To explain parents' concerns over children and media, Cohen's (2002) concept of “moral 
panic" is extensively used. This theory says mass media generate public anxiety, particularly through distortion and over-reporting of certain issues (p.26). Tracing back to history, earlier societies feared television and cinema, then video games and now the Internet. In some early cases (in the 1950s United States), parents agonized about their children's comics, such as Halloween (EC archives ShockSuspenstories, April 1952, p. 69-75). Following this example, it is also worth mentioning that every new media may lead to parental concerns to the brink of panic, but which evaporate soon enough. As suggested by Drotner (1999), "for every time a new mass medium has entered a social scene, it has spurred public debates on social and cultural norms" (p. 596). Nonetheless, the panic varies according to time and context (Buckingham \& Jensen, 2012, p. 417). Therefore, as proposed by scholars, in some ways, this could be a period of adjusting to new media. When the internet is better understood, parents might no longer be so concerned - until a new media emerges. 


\section{References}

Buckingham, D., \& Jensen, H. S. (2012). Beyond "Media Panics." Journal of Children and Media, 6(4), 413-429. doi: 10.1080/17482798.2012.740415

Buckingham, D. (2011). The Material Child-Growing up in consumer culture. Cambridge: Polity Press

Byrne, J., \& Burton, P. (2017). Children as internet users: How can evidence better inform policy debate? Journal of Cyber Policy, (2)1, 39-52. doi:10.1080/23738871.2017.1291698

Byrne, J., Kardefelt-Winther, D., Livingstone, S., \& Stoilova, M. (2016). Global Kids Online research synthesis, 2015-2016. UNICEF Office of Research-Innocenti and London School of

Economics and Political Science. 1 - 75. Available at www.globalkidsonline.net/synthesis

Charmaz, K. (2014). Constructing grounded theory. 2nd Edition. London: SAGE Publications, Inc.

Clark, L.S. (2013).The parent App: Understanding families in the digital age. New York, NY: Oxford University Press.

Cohen, S. (2002). Folk devils and moral panics: The creation of the Mods and Rockers. 3rd edition. New York, NY: Routledge Classics.

Craig, D., \& Cunningham, S. (2017). Toy unboxing: living in a (n unregulated) material world. Media International Australia, 163(1), 77- 86. doi: $10.1177 / 1329878 X 17693700$

Creswell, J.W., \& Creswell, D.J. (2018). Research design: Qualitative, quantitative, and mixed methods approaches. 5th edition. United Kingdom, UK: SAGE Publications, Inc.

Dias, P., Brito, R., Ribbens, W., Daniela, L., Rubene, Z., Dreier, M., Gemo, M., Di Gioia, R., \& Chaudron, S. (2016). The role of parents in the engagement of young children with digital technologies: Exploring tensions between rights of access and protection, from 'Gatekeepers' to 'Scaffolder' European Commission - Joint Research Centre, Italy Global Studies of Childhood, 6 (4), 414-427. doi: 10.1177/2043610616676024

Drotner, K. (1999). Dangerous Media? Panic discourses and dilemmas of modernity. Pedagogical Historical, 35 (3), 593-619. doi: 10.1080/0030923990350303

Eshet-Alkalai, Y. (2004). Digital literacy: A conceptual framework for survival skills in the digital Era. Journal of Educational Multimedia and Hypermedia, 13(1), 93-106.

Facer, K. (2012). After the moral panic? Reframing the debate about child safety online, Discourse: Studies in the Cultural Politics of Education, 33(3), 397-413. doi:10.1080/01596306.2012.681899

Goode, E., \& Ben-Yehuda, N. (1994). Moral Panics: Culture, politics, and social construction. Annual Review of Sociology, 20, 149-171

Haddon, L., \& Vincent, J. (2015). UK children's experience of smartphones and tablets: perspectives from children, parents and teachers. LSE, London, Net Children Go Mobile

Halloween. (April, 1952). EC archives ShockSuspenstories. 69-75.

Helsper, E., H., \& Eynon, R. (2009). Digital natives: where is the evidence? British Educational Research Journal, 1-18. doi: 10.1080/01411920902989227

Ingraham, C., \& Reeves, J. (2016). New media, new panics. Critical Studies in Media Communication, 33(5), 455-467. doi: 10.1080/15295036.2016.1227863

Internet users survey (2017). Statistical brief number 21. Malaysian Communications and Multimedia Commission

Kirwil, L. (2009). Parents' mediation of children's internet use in different European countries. Journal of Children and Media, 3(4), 394-409. doi: 10.1080/17482790903233440 
Livingstone, S. (2007). Do the media harm children? Journal of Children and Media, 1(1), 5-14. doi: 10.1080/17482790601005009

Livingstone, S., \& Haddon, L. (2009). EU Kids Online: Final report. EU Kids Online. LSE, London: Available at: $\underline{w w w . e u k i d s o n l i n e . n e t}$

Livingstone, S., \& Helsper, E. J. (2008). Parents' mediation of children's internet use. Journal of Broadcasting \& Electronic Media, 52 (4), 581-599. doi: 10.1080/08838150802437396

Livingstone, S., Mascheroni, G., Dreier, M., Chaudron, S., \& Lagae, K. (2015). How parents of young children manage digital devices at home: The role of income, education and parents' style. EU Kids Online, LSE: London.

Livingstone, S., Mascheroni, G., \& Staksrud, E. (2015). Developing a framework for researching children's online risks and opportunities in Europe. EU Kids Online. 1 - 21. Available at: $\mathrm{www}$.eukidsonline.net

Livingstone, S., Haddon, L., Görzig, A., \& Ólafsson, K. (2011). Risks and safety on the internet: The perspective of European children. Full Findings. LSE, London: EU Kids Online.

Livingstone. S., \& Bulger, M. (2014). A global research agenda for children's rights in the digital age. Journal of Children and Media, 8 (4), 317-335. doi:10.1080/17482798.2014.961496

McRobbie, A., \& Thornton. S.L. (1995). Rethinking 'Moral Panic' for multi-mediated social worlds. The British Journal of Sociology, 46, (4), 559-574. Blackwell Publishing on behalf of The London School of Economics and Political Science. Available at: http://www.jstor.org/stable/591571

Nikken, P., \& Jansz, J. (2014). Developing scales to measure parents' mediation of young children's internet use. Learning, Media and Technology, 39 (2), 250-266. doi: 10.1080/17439884.2013.782038

Nikken, P., \& Schols, M. (2015). How and why parents' guide the media use of young children. Journal of Children and Family Studies, 24, 3423-3435. doi: 10.1007/s10826-0150144-4

Organization for Economic Co-operation and Development. (2011). The Protection of children online: Risks faced by children online and policies to protect them. OECD Digital Economy Papers, 179. OECD Publishing, Paris. http://dx.doi.org/10.1787/5kgcjf71pl28-en

Paus-Hasebrink, I., Bauwens, J., Dürager, A.E., \& Ponte, C. (2013). Exploring types of parent-child relationship and internet use across Europe. Journal of Children and Media, 7(1), 114-132. doi: 10.1080/17482798.2012.739807

Pew Research Center. (2016). Parents, teens and digital monitoring.

Prensky, M. (2001). Digital Natives Digital Immigrants. On the Horizon, 9 (5), MCB University Press. Available at: www.pewresearch.org

Schofield, C. L. (2011). Parents' mediation theory for the digital age. Communication Theory, 21(4), 323-343. doi:10.1111/j.1468-2885.2011.01391.x

Soldatova, G., \& Zotova, E. (2013). Coping with online risks: The experience of Russian schoolchildren. Journal of Children and Media, 7(1), 44-59. doi:10.1080/17482798.2012.739766

Sonck, N., Nikken, P., \& de Haan, J. (2013). Determinants of internet mediation. Journal of Children and Media, 7(1) 96-113. doi: 0.1080/17482798.2012.739806

Sorbring, E. (2014). Parents' concerns about their teenage children's internet use. Journal of Family Issues, 35(1), 75- 96. doi: 10.1177/0192513X12467754

Staksrud, E., \& Livingstone. S. (2009). Children and online risks. Information, Communication \& Society, 12 (3), 364-387. doi: 10.1080/13691180802635455 
Terras, M. M., \& Ramsay, J. (2016). Family digital literacy practices and children's mobile phone use. Frontiers in Psychology, 7(1957). doi: 10.3389/fpsyg.2016.01957

The Common Sense Census. (2017). Media use by kids age zero to eight. Available at: https://www.commonsensemedia.org/research/the-common-sense-census-media-use-bykids-age-zero-to-eight-2017

The London School of Economics and Political Science. (2015). Mobile opportunities exploring positive mobile media opportunities for European children.

The Office of Communications. (2017). Children and parents: Media use and attitudes. Available at:

https://www.ofcom.org.uk/ data/assets/pdf file/0020/108182/children-parents-mediause-attitudes-2017.pdf

Rubin, H. J., \& Rubin, I. S. (2005). Qualitative interviewing: The art of hearing data. 2nd edition. Thousand Oaks, California: CL: SAGE Publications, Inc.

United Nations Children's Fund. (2014). Exploring the digital landscape in Malaysia: Access and use of digital technologies by children and adolescents.

United Nations Children's Fund. (2017). The state of the world's children: Children in a digital world Available at: https://www.unicef.org/publications/index_101992.html 